\title{
WHAT DO GENERAL NEUROLOGISTS NEED TO KNOW ABOUT NEUROPATHIC PAIN?
}

\author{
Pedro Schestatsky', Osvaldo José M. Nascimento ${ }^{2}$
}

\begin{abstract}
Neuropathic pain (NP) is defined as pain caused by lesion or dysfunction of the somatosensory system, as a result of abnormal activation of the nociceptive pathway (small fibers and spinothalamic tracts). The most common causes of this syndrome are the following: diabetes, post-herpetic neuralgia, trigeminal neuralgia, stroke, multiple sclerosis, spinal cord injury, HIV infection, cancer. In the last few years, the NP has been receiving special attention for two main reasons: (1) therapeutical refractoriness of a variety of pain syndromes with predominant neuropathic characteristics and (2) the development of diagnostic tools for neuropathic pain complaints. The present review article provides relevant information on the understanding and recognition of NP, as well as evidence-based therapeutic approaches.
\end{abstract}

KEY WORDS: neuropathic pain, nociceptive pain, diagnosis, treatment.

\section{O que os neurologistas gerais devem saber sobre dor neuropática?}

Resumo - A dor neuropática (DN) é definida como dor causada por lesão ou disfunção do sistema somatossensitivo, como resultado da ativação anormal da via nociceptiva (fibras de pequeno calibre e trato espinotalâmico). As principais causas desta sindrome são: diabetes, neuralgia pós-herpética, neuralgia trigeminal, acidente vascular encefálico, esclerose múltipla, trauma raquimedular, infecção por HIV, câncer. Nos últimos anos, a DN vem recebendo especial atenção por dois motivos principais: (1) refratariedade terapêutica de várias síndromes dolorosas com componentes neuropáticos predominantes e (2) desenvolvimento de ferramentas diagnósticas para o reconhecimento deste tipo de dor. $O$ presente artigo de revisão fornece informações relevantes para o entendimento e reconhecimento da DN, bem como de abordagens terapêuticas baseadas em evidência.

PALAVRAS-CHAVE: dor neuropática, dor nociceptiva, diagnóstico, tratamento.

Pain is defined as an unpleasant emotional experience related to potential or real tissue damage', being classified as "nociceptive" or "neuropathic" pain types. Nociceptive pain is caused by physiological activation of pain receptors and it is related to musculoskeletal tissue damage i.e., osteoarthritis, hand trauma and so forth ${ }^{2}$. Neuropathic pain (NP), on its turn, is defined as pain initiated by a lesion or dysfunction of the somatosensory system, resultant from abnormal activity of the nociceptive pathway. This pathway is formed by small fibers and spinothalamic tracts up to cerebral cortex ${ }^{4}$ (Fig 1). More recently, because of the possible coexistence of both types of pain, some authors recommend the use of the term predom- inant neuropathic or predominant nociceptive types of pain, depending on the predominant clinical picture ${ }^{2}$.

\section{EPIDEMIOLOGY}

A recent survey analysing 6.000 adults from the primary health system of the United Kingdom, found a prevalence of $8.2 \%$ of pain with predominant neuropathic characteristics ${ }^{5,6}$. Such prevalence represented approximately $17 \%$ of all chronic pain patients, mainly composed by women and elderly people of low social and economic levels. However, the prevalence of NP will probably increase in the near future because of the growing number of elderly people and patients with chronic diseases as-

\footnotetext{
${ }^{1} \mathrm{MD}$, PhD, Department of Neurology, Hospital de Clínicas de Porto Alegre, Porto Alegre RS, Brazil; ${ }^{2} \mathrm{MD}$, PhD, Department of Neurology, Fluminense Federal University, Niterói RJ, Brazil.
}

Received 4 March 2009, received in final form 9 May 2009. Accepted 11 June 2009.

Dr. Pedro Schestatsky - EMG Unit. Neurology Department / Hospital de Clínicas de Porto Alegre - Rua Ramiro Barcelos 2600 - 90035 -003 Porto Alegre RS - Brasil. E-mail: pedro.schestatsky@gmail.com 


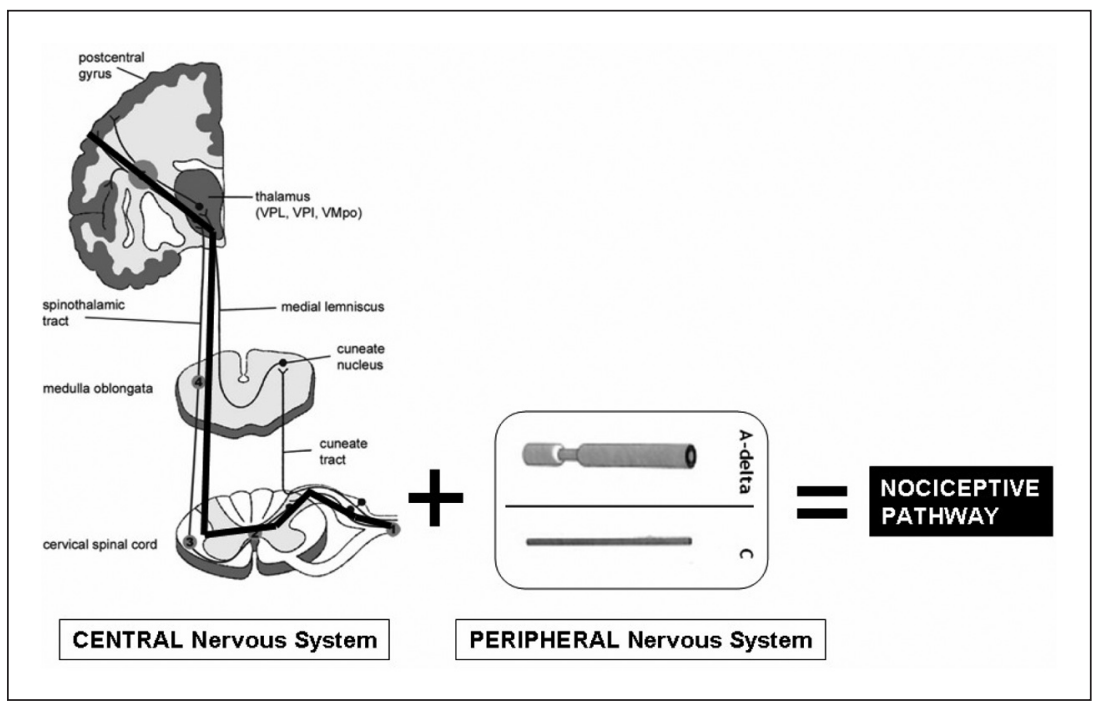

Fig 1. The nociceptive pathway: small fiber and spinothalamic tracts up to cerebral cortex (Modified from Treede ${ }^{4}$, 2003.)

Table 1. Most common causes of neuropathic pain (modified from Bennett ${ }^{5}$, 2006).

\begin{tabular}{lll}
\hline Pain topography & Structure involved & Examples \\
\hline Peripheral nervous system & Nerve & Diabetic neuropathy \\
& & Trigeminal neuralgia \\
& Complex regional pain syndrome \\
& Neuropathy induced by tumoral invasion \\
& Chronic entrapment (i.e., carpal tunnel syndrome) \\
& Dorsal root & Post-herpetic neuralgia \\
& Traumatic brachial plexus avulsion \\
Central nervous system & Prain & Post-stroke \\
& Sultiple sclerosis \\
& Spinal cord & Spinal ischemia \\
& & Syringomyelia \\
\hline
\end{tabular}

sociated with pain, such as cancer, AIDS and diabetes ${ }^{7,8}$. Overall, the most common cause of NP is diabetes mellitus ${ }^{9,10}$. More recently, some authors reported a high prevalence of this kind of pain in patients with glucose intolerance or prediabetes ${ }^{11}$. Table 1 shows the most common causes of peripheral and central NP.

\section{PHYSIOPATHOLOGY}

There are more than 20 postulated theories trying to clarify the mechanisms underlying NP ${ }^{12}$. However, most of them are based on complex neurochemical models ${ }^{9,13}$, that are difficult to translate for clinical practice. The consequence of such complexity and lack of knowledge on NP mechanisms is the low efficacy of pharmacological drugs available for NP (only 30 to $50 \%$ of pain relief), observed in recent meta-analysis ${ }^{14}$. In the opinion of the present authors and other colleagues ${ }^{7,15}$, another reason for the persistent refractoriness of NP treatments is the excessive emphasis on the study of central sensitization phenom- enon as the main cause of NP. Such theory was based on several studies with important methodological problems that have gained huge popularity ${ }^{7,15}$. However, according to Occam's law" ("the simplest theory is to be preferred over the complicated one"), the most plausible and convincing theory for NP comprehension is the ectopic generation of impulses coming from $\mathrm{C}$ mechano-insensitive fibers which leads to positive neuropathic symptoms including pain ${ }^{1718}$. Right after a nerve lesion, some patients may develop changes in $\mathrm{Na}+$ ion channels that leads to an axonal hyperexcitability and painful symptoms. Indeed, sodium channel dysfunction, seems to be the basis of genetic predisposition to chronic pain ${ }^{19}$. Apart from the primary lesion site, axonal hyperexcitability sometimes also occur far away from the nerve injury region, or even in healthy and distant nerves (ectopic nerve discharges), causing apparently unexplained pain syndromes ${ }^{7,10}$. Indeed, NP may be relieved by antiepileptic agents, such as carmazepine or gabapentine, that block Na+ channels ${ }^{14}$. 


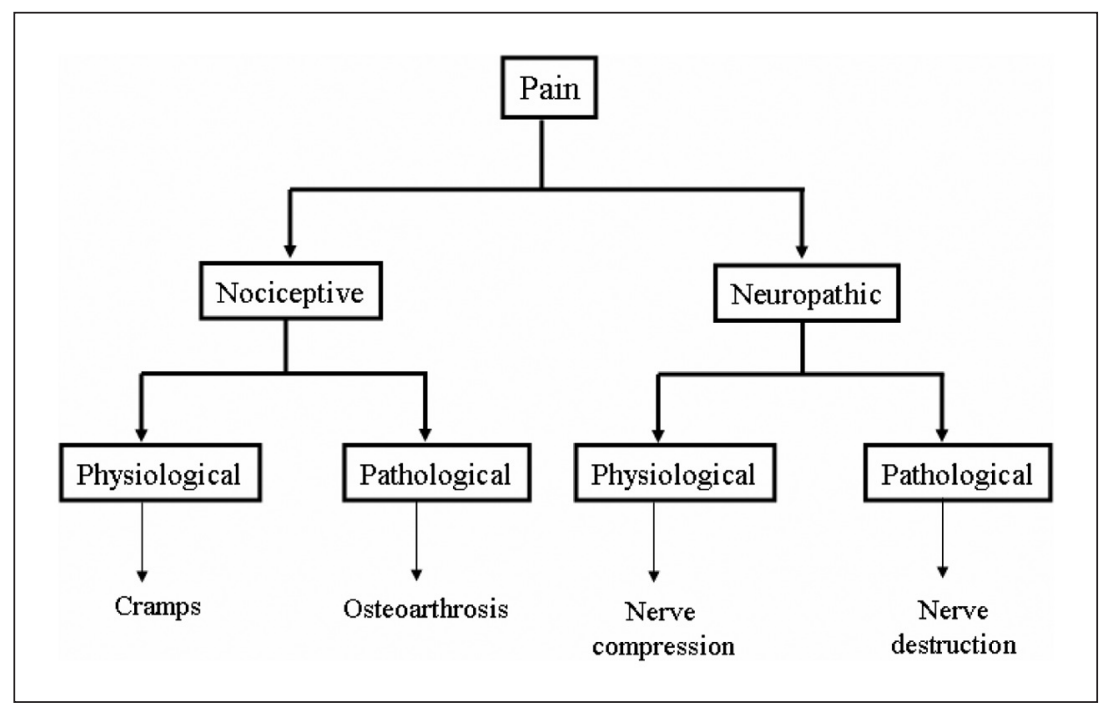

Fig 2. Levels of accuracy of the neuropathic pain diagnosis (Modified from Treede ${ }^{8}$ et al., 2007).

Table 2. Differences between nociceptive and neuropathic pain (modified from Serra , 2006).

\begin{tabular}{lll}
\hline Pain types & Nociceptive & Neuropathic \\
\hline Definition & $\begin{array}{l}\text { Pain caused by physiological } \\
\text { activation of pain receptors }\end{array}$ & $\begin{array}{l}\text { Pain caused by lesion or dysfunction of } \\
\text { the somatosensory system, especially } \\
\text { the nociceptive pathway }\end{array}$ \\
$\begin{array}{ll}\text { Mechanism } \\
\text { Localization }\end{array}$ & $\begin{array}{l}\text { Natural physiological transduction } \\
\text { Local + referred pain }\end{array}$ & $\begin{array}{l}\text { Ectopic impulse generation, among others } \\
\text { Confined to innervation territory of } \\
\text { the lesioned nervous structure }\end{array}$ \\
Quality of symptoms & $\begin{array}{l}\text { Ordinary painful sensation } \\
\text { (good verbal descriptors) }\end{array}$ & $\begin{array}{l}\text { New strange sensations } \\
\text { (poor verbal descriptors) }\end{array}$ \\
Treatment & $\begin{array}{l}\text { Good response } \\
\text { (conventional analgesics) }\end{array}$ & Poor-moderate response \\
& (antidepressants, antiepileptics)
\end{tabular}

In fact, some neurologists considered NP to be "an epilepsy of the nerve that responds satisfactorily to anticonvulsivants".

\section{DIAGNOSIS}

Identifying NP in clinical practice is not an easy task. The painful sensation cannot be objectively measured and there is no universal consensus for the diagnosis of such condition. However, some authors proposed a practical algorithm for $\mathrm{NP}^{8}$, in which three levels of diagnostic certainty are considered: possible, probable or definitive diagnosis of NP (Fig 2). Nociceptive pain and NP coexist in most of painful conditions and their identification is crucial. Neuropathic pain demands specific analgesic approaches, quite different from the traditional approach to nociceptive pain type. An illustrative example is a diabetic patient with osteoarthrosis. In this case, the pain can be resultant from three possibilities: (A) small fiber dysfunction, (B) activation of pain receptors due to bone damage, or (C) both of them. A careful clinical evaluation can guide to a more rational and efficient therapeutic strategy for such kind of patient. Table 2 shows the main differences between neuropathic and nociceptive types of pain that could help to separating both entities?

\section{SYMPTOMS}

Patients with NP can have multiple and complex sensory complaints. Differently from nociceptive pain, there are poor verbal descriptors for characterizing NP. Most patients report their symptoms using analogies ("Doctor, my pain is like a..."). Such complaints are divided in spontaneous and evoked sensory symptoms. Spontaneous pain, on its turn, can be subdivided into continuous or paroxistic ones. The latter is frequently, but not always, felt as if it is located at the superficial skin level and it is described in terms of dysaesthesias, such as burning, tingling, pricking and stabbing characteristics ${ }^{5}$.

\section{SIGNS}

Abnormal and plausible findings on sensory exami- 


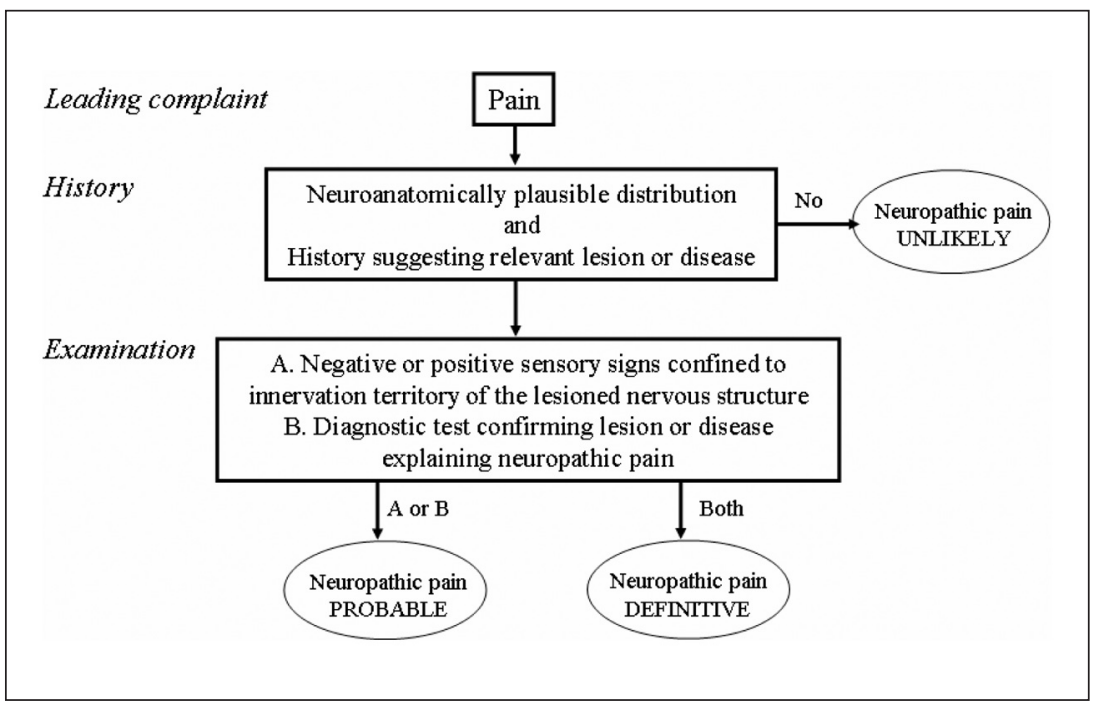

Fig 3. Clinical picture of neuropathic pain (Bennett ${ }^{5}$, 2006).

Table 3. Bedside tests and quantitative sensory testing (QST) for different sensations conveyed by different types of sensory fibers (modified from Cruccu et al. ${ }^{3}, 2004$ )

\begin{tabular}{llll}
\hline Fibers & Sensation & Bedside examination & QST \\
\hline $\mathrm{A} \beta$ & Light touch & Cotton wool & Von Frey filaments \\
& Vibration & Tuning fork $(128 \mathrm{~Hz})$ & Vibrometer \\
$\mathrm{A} \delta$ & First pain & Needles and & Thermotest, CASE IV \\
& and cold & "Thermorolers" & \\
$\mathrm{C}$ & Second pain & & \\
& and warm & & \\
\hline
\end{tabular}

nation in a patient with peculiar pain suggest the diagnosis of $\mathrm{NP}^{10}$. Other neurological signs, such as hyper/ hypotony, focal paralysis and plantar cutaneous reflexes, among others, will also help to suggest the topography of pain (central vs. peripheral) in a patient with neuropathic symptoms. In order to improve the value of sensory findings in the diagnosis of NP, it is useful to classify them in negative, positive and autonomic phenome$\mathrm{na}^{5}$, as seen in Figure 3.

Negative phenomena result from loss of light touch, vibration and thermoalgesic senses. These sensations are mediated by large myelinated $A \beta$ (light touch and vibration), small poorly myelinated $A \delta$ (cold and first pain) and unmyelinated type $C$ fibers (warm and second pain). In order to assess the function of each type of fiber, bedside maneuvers and psychophysical tests (Table 3 ) can be employed ${ }^{3}$.

Positive phenomena of NP can be presented spontaneously, evoked by sensory stimuli, or in combination. The most frequent described positive symptoms in clinical practice are the following ${ }^{5,710}$ : (1) Allodynia: pain due to stimulus which does not normally cause pain. Three types of allodynia are described, based on the precipitant stimulus: mechanical (or tactile), thermal (warm and cold) and kinetic (movement); (2) Hyperalgesia: painful sensation of abnormal intensity in response to a nociceptive stimulus. Allodynia and hyperalgesia oftenly coexist in practice and it can be difficult to differentiate the two. Both symptoms are considered essential features for NP, but they can also be present in the nociceptive type of pain; (3) Hyperpathia: painful reaction to repetitive nociceptive and non-nociceptive stimuli or prolonged pain sensation in response to nociceptive stimuli (aftersensation phenomenon); (4) Autonomic hyperactivity: abnormal blood flow, cutaneous temperature and sweating can accompany painful states and contribute for its persistence. Trophic abnormalities can usually be developed in chronic pain states, such as seen in complex regional pain syndromes.

\section{NEUROPATHIC PAIN SCALES}

Verbal pain descriptor scales can provide important information to the assessment process alongside clinical history examination and investigation ${ }^{5}$. These scales also provide standardized symptoms assessment for pain research and follow-up for NP treatments. Several scales have been published, with especial emphasis on NP intensity, such as the Neuropathic Pain Scale ${ }^{20}$, Neuropathic Pain Questionnaire ${ }^{21}$ and Douleur Neuropatique $4^{22}$. More recently, the Leeds Assessment of Neuropathic Symptoms 


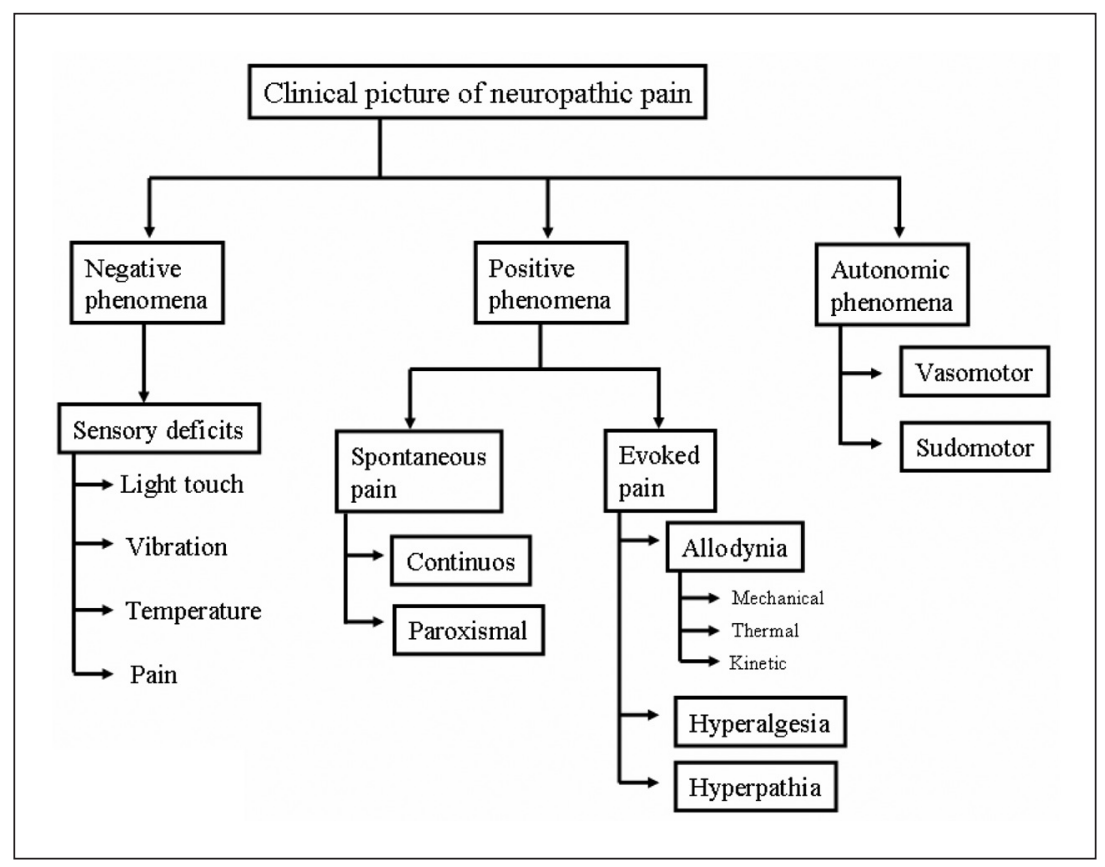

Fig 4. Absent laser-evoked potentials in a patient with Wallenberg syndrome, supporting the diagnosis of neuropathic pain (From Hospital Clínic of Barcelona, 2005).

Table 4. Drugs for neuropathic pain (modified from Finnerup ${ }^{14}$ et al., 2005 and Beniczky ${ }^{51}$ et al., 2005).

\begin{tabular}{llll}
\hline Neuropathic pain & Drug & NNT (Cl 95\%) & Recommended doses \\
\hline Peripheral & Tricyclics & $2.2(1.9-2.6)$ & Up to $150 \mathrm{mg} /$ day \\
& SNRI & $6.8(3.4-441)$ & Up to $80 \mathrm{mg} /$ day \\
& Gabapentin & $4.4(3.4-6.2)$ & 600 a $1200 \mathrm{mg} 3 \times /$ day \\
& Pregabalin & $5.0(3.5-8.6)$ & 50 a $100 \mathrm{mg} 3 \times /$ day \\
& Tramadol & $3.9(2.7-6.7)$ & $200-400 \mathrm{mg} /$ day \\
& Oxicodone-CR & $2.6(1.9-4.1)$ & $60-120 \mathrm{mg} /$ day \\
& Topical Lidocaine & $4.4(2.5-17.5)$ & Patch or gel $5 \%$ (12 hs/day) \\
& Carbamazepine & $1.8(1.4-2.7)$ & Up to $1000 \mathrm{mg} /$ day \\
Central & $4.0(2.6-8.5)$ & Up to $75 \mathrm{mg} /$ day \\
& Tricyclics & $2.9(1.3-5.0)$ & Up to $200 \mathrm{mg} /$ day \\
& Lamotrigine & $3.4(1.7-105)$ & Up to $1000 \mathrm{mg} /$ day \\
\hline
\end{tabular}

NNT: number needed to treat to relieve of at least $50 \%$ of pain intensity; $\mathrm{Cl}$ : Confidence Interval; SNRI: serotonin noradrenaline reuptake inhibitors.

and Signs Scale $e^{23}$ has been used as an index of predominant neuropathic vs. nociceptive pains. Such an instrument it is in validation process for Portuguese language in our center ${ }^{24}$.

\section{MOST COMMON NEUROPATHIC PAIN SYNDROMES}

Peripheral

Diabetic neuropathy - Burning feet sensation that gets worse during the night is the typical clinical picture. The prevalence of NP in distal simetric polyneuropathy is $1-10 \%$, depending on the degree of small fiber involvement ${ }^{25}$. Rarely, pain occurs in the absence of large fiber signs and symptoms since small fibers are usually dysfunctional at early stages of the diabetic neuropathy.

Trigeminal neuralgia - Sudden, severe and usually unilateral stabbing pain with V2 or V3 distribution of the V cranial nerve. Eighty percent of the cases are idiopathic, but $66 \%$ of these have evidence of vascular compression at the root entry zone ${ }^{26}$. Other causes include demyeliniation secondary to multiple sclerosis, angioma, brainstem infarcts and tumors, such as acoustic neurinoma.

Post-herpetic neuralgia - Persistent pain over the skin affected area that could last for more than 12 weeks after the healing of typical skin lesions, especially in elderly patients. Pain may be disabling and recurs in months or even 


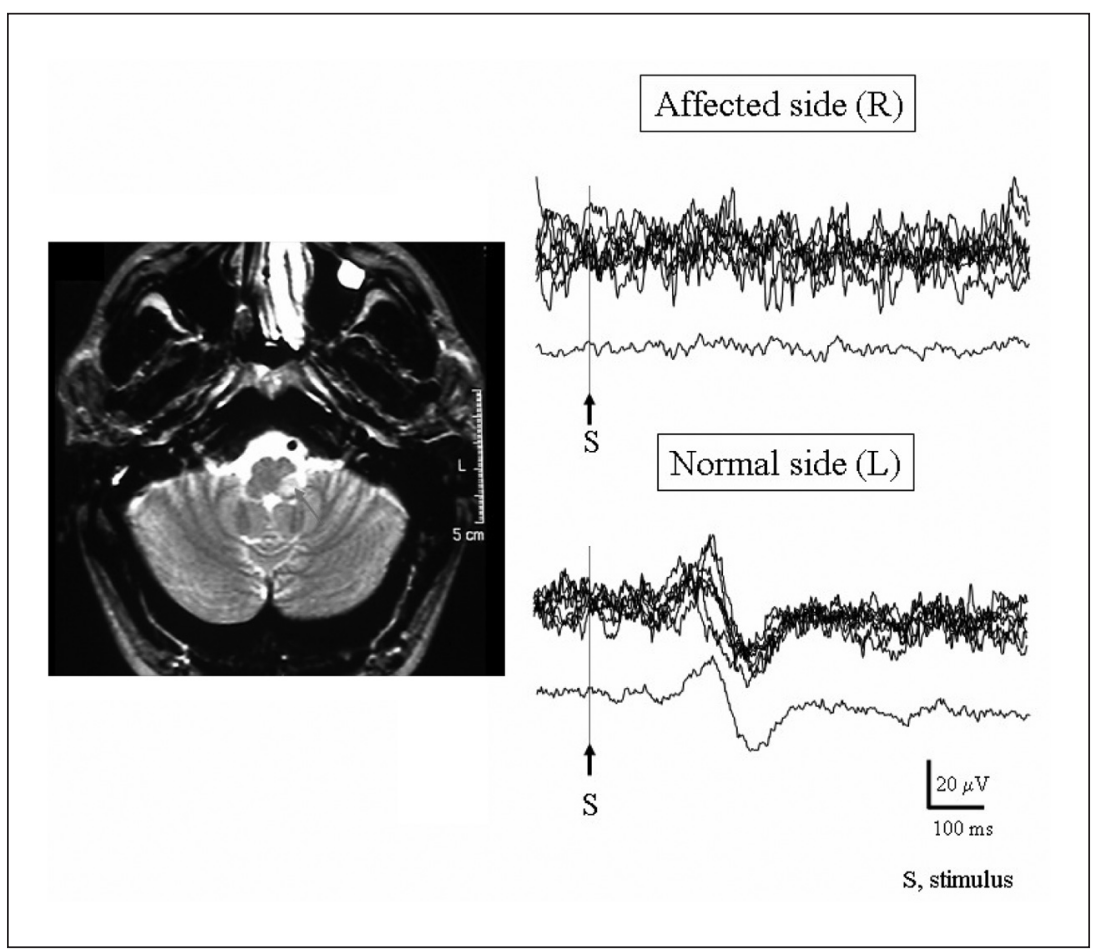

Fig 5. (A) Normal thermal thresholds in the quantitative sensory testing for temperature; (B) The most common patterns of QST abnormalities. years later. Both peripheral and central mechanisms contribute to the process ${ }^{27}$.

Cancer - Pain can be due to nerve lesion caused by direct tumoral invasion, but also in case of secondary to fibrosis or myelopathy post-radiotherapy, chemotherapy or surgery, especially in cases of radical mastectomy or thoracotomy ${ }^{5}$. Paraneoplastic painful neuropathies can precede tumor detection by months or years.

Drugs - Most of drug-induced neuropathies are of axonal type, with a predilection for sensory nerves distally. The sensory injury can affect either large or small fibers. The most common drugs implicated in neuropathic pain are the following ${ }^{5}$ : vincristine, zalcitabine and stavudine. The treatment relies in durg interruption and the prognosis is usually good.

\section{Central}

Any spinal-thalamic-cortical lesion can cause NP regardless its etiology (ischemic, inflamatory, infeccious and so on). Loss of pain descending inhibition is a less known physiopathological mechanism ${ }^{28}$ and can contribute for NP maintenance in some patients with Parkinson's disease $^{29}$. Stroke, multiple sclerosis and other myelopathies are the most common causes of central NP. This type of pain is wrongly considered a rarity, since it occurs in $8 \%$ of patients with stroke ${ }^{30}, 28 \%$ with multiple sclerosis, $75 \%$ with syringomyelia ${ }^{31}$ and $70 \%$ with myelopathy ${ }^{30}$. Tactile and cold allodynia are frequently seen in such patients.

Approximately $70 \%$ of patients with post-stroke pain describe their pain in whole hemibody, ipsilateral to mo- tor and sensory deficits ${ }^{31}$. There is no pathognomonic characteristic of central NP. However, the pain is almost always dysaesthetic ("painful paresthesias"). Other aggravating factors are the psychiatric comorbities, commonly seen in patients with chronic pain, such as major depression and anxiety that usually amplify pain perception ${ }^{10}$. Central pain can initiate right after a structural damage, or it can take 2-3 years to arise after the insult. This may explain why central NP is so non-recognized in clinical practice. Figure 4 shows a patient with pain secondary to Wallenberg syndrome who had absent laser-evoked potentials contralateral to the neuropathic symptoms, indicating a lesion of the nociceptive pathway.

\section{LABORATORY TESTS}

Since NP results from lesion or dysfunction of small fiber or spinothalamic tracts (nociceptive pathway), complementary exams are used for direct or indirect demonstration of lesion or dysfunction of the nociceptive pathway.

The quantitative sensory testing (QST) for temperature and pain helps to evaluate the nociceptive pathway as a whole, from the thermal receptor, through small fibers and spinothalamic tracts and up to patient's verbal expression of his/her perception. This is done using thresholds determination for different sensations ${ }^{32}$. By means of a thermode with a temperature rising velocity of 1 to $4^{\circ} \mathrm{C} / \mathrm{s}$, placed over the skin affected by the pain, the patient is asked to press a button when he/she feels the sensation of cold, warm, cold pain and heat pain (Fig 5A). Posteriorly, the same procedure is repeated over the contral- 


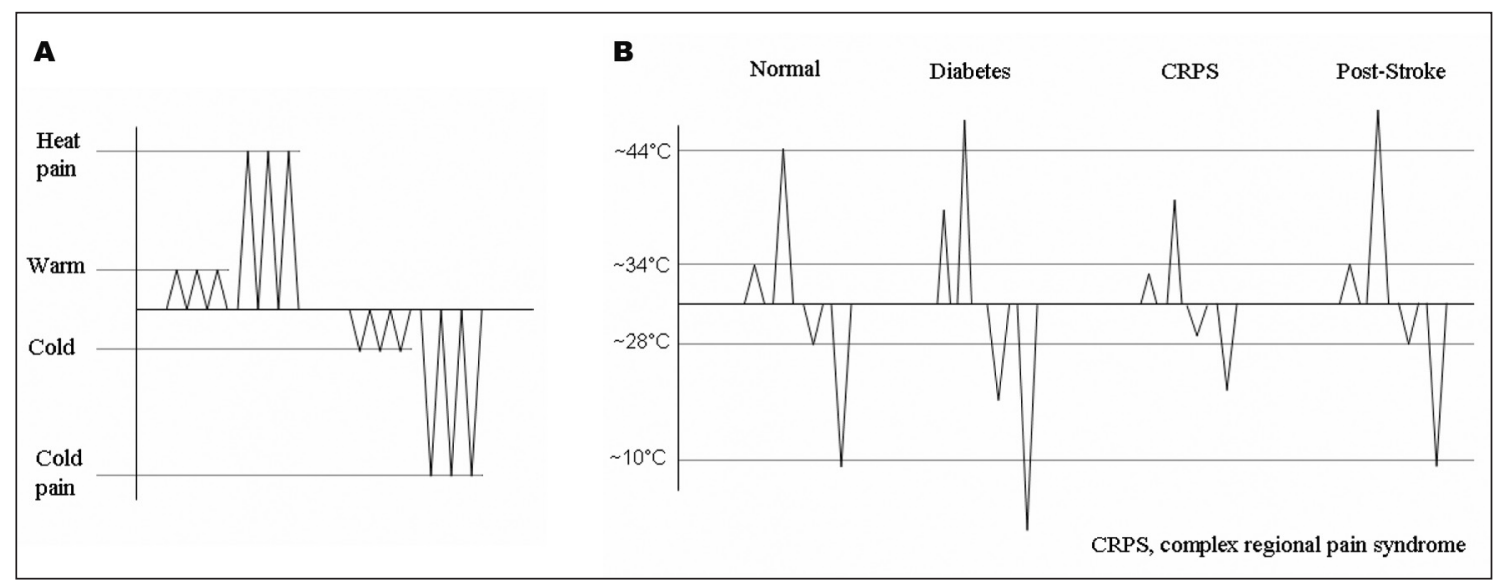

Fig 6. Small amplitude contact-evoked heat potentials applied in the symptomatic side of a patient with meralgia paresthetica (Schestatsky et al. $\left.{ }^{44}, 2008\right)$.

ateral area, for comparison purposes. Abnormal thermal thresholds (Fig 5B) signalize a lesion in any level of the nociceptive pathway, potentially causing NP symptoms.

Nerve conduction studies and electromyography - Although this method does not assess small fiber function, abnormal findings suggest a neuropathic process in a patient with pain ${ }^{10,33,34}$. For example: an altered test in a diabetic patient with burning pain suggest a real NP since the small fibers usually are affected before the large fibers in the natural history of diabetic neuropathy ${ }^{35}$.

Microneurography - With a tungsten needle within the nerve and using a specific stimulation techniques it is possible to identify and to record the activity of five subtypes of $C$ fiber populations. By means of this method, Bostock and $\mathrm{cols}^{18}$ described the presence of double spikes from mechano-insensitive $C$ fibers in NP patients. This finding was considered to be a reliable marker of peripheral NP. Unfortunately, microneurography, a powerful tool for research, is too complex and time consuming to be used in clinical practice ${ }^{3}$.

Nociceptive RIII reflex - By means of single or repetitive electrical stimuli of the sural nerve it is possible to obtain electromyographic responses recorded at femoral biceps at latencies around 90 to $130 \mathrm{~ms}$. The electrical threshold for its appearance and its maximal amplitude are measured ${ }^{7,34,36}$. Because of its straight correlation with pain perception, the RIII responses have been used for monitoring the efficacy of pharmacological treatments for $\mathrm{NP}^{3}$.

Autonomic reflexes - Besides carrying afferent signals of pain and temperature, the $C$ fibers are also involved with autonomic control (C efferent autonomic fibers) and its analysis can help in the etiological diagnosis of pain $^{33,37}$. The sympathetic skin response (SSR) is an autonomic reflex mediated by $\mathrm{C}$ efferent autonomic fibers ${ }^{29,34}$. Action potentials are analyzed with respect to amplitudes and latencies. More recently, the analysis of SSR morphology and habituation have been used for a better QST interpretation ${ }^{38}$ and for the functional assessment of pain descending inhibition ${ }^{29}$.

Laser-evoked potentials (LEPs) - By means of scalp electrodes, long latency brain potentials can be recorded in response to laser stimuli given on the skin, allowing the study of peripheral and central conduction of nociceptive fibers ${ }^{4}$. Abnormal LEPs (Fig 4) are seen in patients with hemibody sensory syndromes, in which structural and asymmetrical lesions of the spinothalamic tract are found i.e., Wallenberg's syndrome ${ }^{39}$ or syringomyelia ${ }^{40}$. According to some authors, a lesion of the spinothalamic tract, demonstrable by abnormal LEPs is required for the establishment of NP diagnosis ${ }^{41,42}$. The only drawback of this method is the undesirable burning of the skin after repetitive stimuli in the same spot.

Contact-evoked heat potentials (CHEPS) - Differently from the slow rising temperature thermode of QST, the thermode of this device is capable to increase the skin temperature with $70^{\circ} \mathrm{C} / \mathrm{s}$ and, consequently, to generate long latency brain potentials. One of the main advantages of the CHEPS in comparison with LEPs is the absence of cutaneous lesions after several stimuli ${ }^{43}$. Recently, we observed small amplitude CHEPS in patients with painful nerve entrapment of the thigh ${ }^{44}$, supporting the neuropathic character of pain complaints in meralgia paresthetica at latter stages (Fig 6A, 6B).

Functional neuroimaging - Functional magnetic ressonance image ( $\mathrm{fMRI}$ ) and positron emission tomography (PET) have been contributing for the mapping of cerebral regions activated by nociceptive stimuli ("pain matrix"). These regions include the secondary somatosensory (SII), insular and cingulate cortex, as well as the upper brainstem. Less consistently, the contralateral thalamus and primary somatosensory are also considered pain matrix regions ${ }^{45}$. There is converging evidence that spontaneous NP is associated with less activity in contralat- 


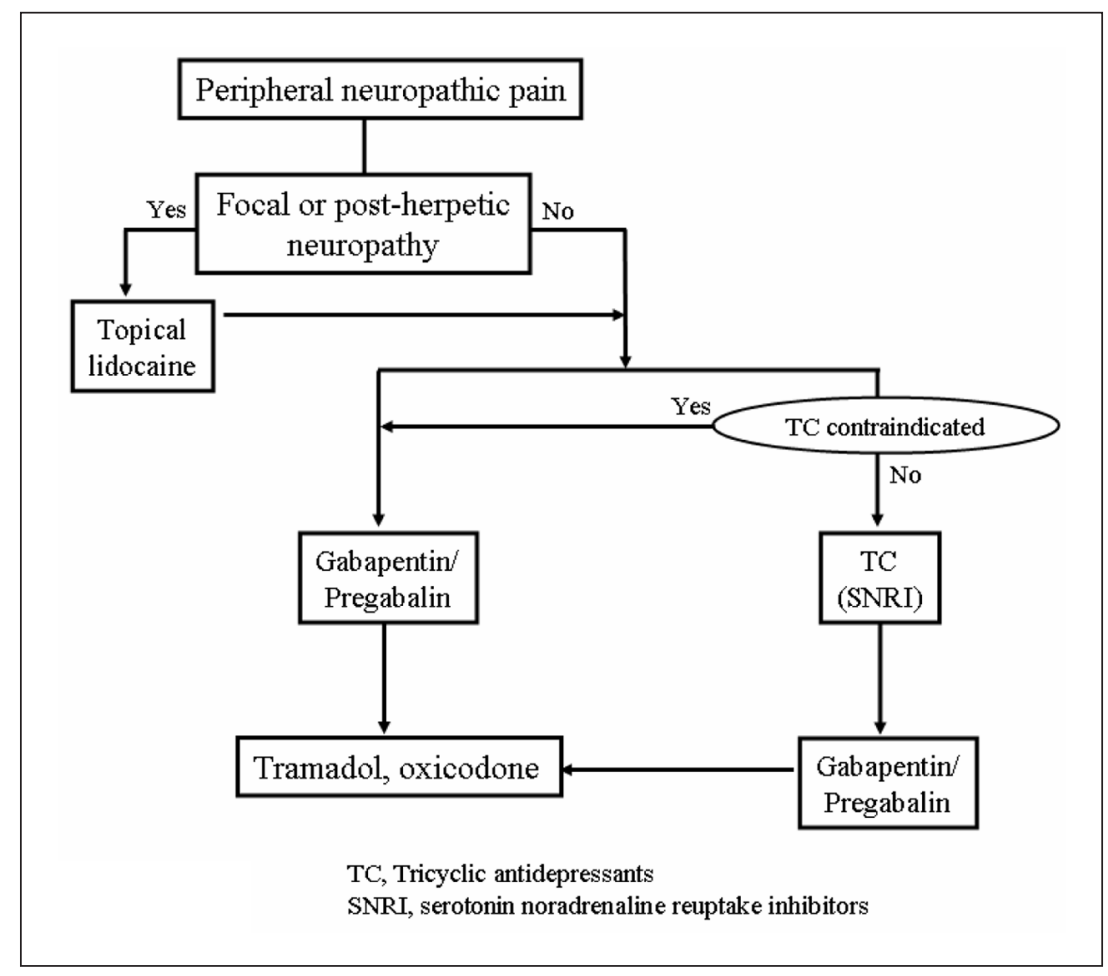

Fig 7. Rational approach for pharmacological treatment of neuropathic pain (Finnerup et al. $\left.{ }^{14}, 2005\right)$. eral thalamus, whereas evoked pain is more associated with an increased activity in thalamic, insular and somatosensry regions ${ }^{3}$.

Skin punch biopsy - It allows the $C$ fiber quantification by measuring the intra-dermal $C$ fiber density. Loss of $C$ fibers detected with the skin biopsy was seen in a large number of neuropathies ${ }^{46,47}$. The skin biopsy performed by the punch technique is an easy and reliable method for the follow-up of NP patients, but it is unavailable in most medical centers throughout the world. Fortunately, there is a good correlation between intra-dermal C fiber density and CHEPS' amplitude ${ }^{48}$, a less invasive and more accessible method when compared o skin biopsy.

\section{TREATMENT}

Recent studies have shown that most of patients treated for NP receive drugs with non-proved clinical efficacy or in inadequate dosages of appropriate medication ${ }^{49,50}$. NP is usually refractory to ordinary analgesics. Tryciclic antidepressants and anticonvulsivants are the mainstay in the treatment of NP, regardless its topography (central vs. peripheral) and its etiology. Figure 7 shows a rational algorithm for the approach of patients with peripheral NP. Such an algorithm can also be used for patients with central NP ${ }^{14}$ with addition of few specific drugs, such as showed in Table $4^{14,51}$.

Other treatment modalities, such as sensory stimulation (transcutaneous electrical nerve stimulation or TENS, spinal cord stimulation, deep brain stimulation) and sur- gery (thoracic sympathectomy, chordotomy, radicular neurolysis etc) are available in some centers, destinated to refractory patients ${ }^{52-54}$, but there is no strong enough evidence for a systematical recommendation ${ }^{5,55}$. More recently, transcranial magnetic stimulation of the motor cortex has been proposed in some forms of $\mathrm{NP}^{56}$, in order to modulate painful symptoms through cortical reorganization. However, up to now, there are no definitive conclusions about the role of magnetic stimulation that could allow its wider utilization in clinical practice.

\section{FINAL CONSIDERATIONS}

The three most important messages of this paper are: (1) NP is prevalent, frequently unrecognized and poorly treated; (2) A lesion in the somatosensory system - especially the nociceptive pathway - is required for the diagnosis of NP and (3) Neurologists have an important role in the approach of pain patients because of its capacity to detect subtle abnormalities in the neurological assessment that will support or not the diagnosis of NP.

\section{REFERENCES}

1. Merskey H, Bogduk N. Classification of chronic pain. Seattle: IASP Press, 1994.

2. Bennett MI, Smith BH, Torrance N, Lee AJ. Can pain can be more or less neuropathic? Comparison of symptom assessment tools with ratings of certainty by clinicians. Pain 2006;122:289-294.

3. Cruccu G, Anand P, Attal N, et al. EFNS guidelines on neuropathic pain assessment. Eur J Neurol 2004;11:153-162.

4. Treede RD. Neurophysiological studies of pain pathways in peripheral and central nervous system disorders. J Neurol 2003;250:1152-1161. 
5. Bennett MI. Theories, history and current taxonomy. In: Bennett MI (Ed). Neuropathic pain. Oxford University Press, 2006;3-9.

6. Torrance N, Smith BH, Bennett MI, Lee AJ. The epidemiology of chronic pain of predominantly neuropathic origin. Results from a general population survey. J Pain 2006;7:281-289.

7. Serra J. El dolor neuropático. In: Serra J (Ed). Tratado del dolor neuropático. Madrid: Panamericana, 2006.

8. Treede RD, Jensen TS, Campbell JN, et al. Neuropathic pain: redefinition and grading system for clinical and research purposes. Neurology. 2007;70:1630-1635.

9. Woolf CJ, Mannion RJ. Neuropathic pain, aetiology, symptoms, mechanisms and management. Lancet 1999;353:1959-1964.

10. Schestatsky P, Ehlers JA. Dor Neuropática. In: Chaves ML, Finkelsztejn A, Stefani MA (Eds). Rotinas em Neurologia e Neurocirurgia. $1^{\text {a }}$ Ed. Porto Alegre. Editora Artmed, 2008;757-767.

11. Smith AG, Singleton JR. Impaired glucose tolerance and neuropathy Neurologist 2008;14:23-29.

12. Devor M. Neuropathic pain: what do we do with all these theories? Acta Anaesthesiol Scand 2001;45:1121-1127.

13. Woolf CJ, Salter MW. Neuronal plasticity: increasing the gain in pain. Science 2000;288:1765-1768.

14. Finnerup NB, Otto M, McQuay HJ, Jensen TS, Sindrup SH. Algorithm for neuropathic pain treatment: an evidence based proposal. Pain 2005;218:289-305.

15. Ochoa JL. Pain mechanisms in neuropathy. Curr Opin Neurol 1994;7: 407-414.

16. Jefferys WH, Berger JO. Ockham's razor and Bayesian statistics. Amer Scientist 1991;80:64-72.

17. Serra J, Campero M, Bostock H, Ochoa J. Two types of C nociceptors in human skin and their behavior in areas of capsaicin-induced secondary hyperalgesia. J Neurophysiol 2004;91:2770-2781.

18. Bostock H, Campero M, Serra J, Ochoa JL. Temperature-dependent double spikes in C-nociceptors of neuropathic pain patients. Brain 2005;128:2154-2163.

19. Dib-Hajj SD, Yang Y, Waxman SG. Genetics and molecular pathophysiology of $\mathrm{Na}$ (v)1.7-related pain syndromes. Adv Genet 2008;63:85-110.

20. Galer BS, Jensen MP. Development and preliminary validation of a pain measure specific to neuropathic pain: the Neuropathic Pain Scale. Neurology 1997;48:332-338.

21. Krause SJ, Backonja MM. Development of a neuropathic pain questionnaire. Clin J Pain 2003;19:306-314.

22. Bouhassira D, Attal N, Alchaar H, et al. Comparison of pain syndromes associated with nervous or somatic lesions and development of a new neuropathic pain diagnostic questionnaire (DN4). Pain 2005;114:29-36.

23. Bennett M. The LANSS Pain Scale: the Leeds assessment of neuropathic symptoms and signs. Pain 2001;92:147-157.

24. Schestatsky P, Felix-Torres V, Ehlers B, Camozzato AL, Nascimeno O, Chaves ML. Validação da Escala LANSS para a língua portuguesa. In process.

25. Little AA, Edwards JL, Feldman EL. Diabetic neuropathies. Pract Neurol 2007;7:82-92

26. Cruccu G, Biasiotta A, Galeotti F, Iannetti GD, Truini A, Gronseth G. Diagnostic accuracy of trigeminal reflex testing in trigeminal neuralgia Neurology 2006;66:139-141.

27. Truini A, Galeotti F, Haanpaa M. Pathophysiology of pain in postherpetic neuralgia: a clinical and neurophysiological study. Pain 2008;140:405-410.

28. Millan MJ. Descending control of pain. Prog Neurobiol 2002;66:355-474

29. Schestatsky P, Kumru H, Valls-Solé J, et al. Neurophysiologic study of central pain in patients with Parkinson disease. Neurology 2007;69:2162-2169.

30. Bonica JJ. Introduction: semantic, epidemiologic, and educational issues. In: Casey KL (Ed) Pain and central nervous system disease: the central pain syndromes. New York: Raven Press 1991:13-29.

31. Boivie J. Central pain. In: Wall PD, Melzak R (Eds) Textbook of pain. Edinburgh: Churchill Livingstone, 1999:879-914.

32. Fruhstorfer $\mathrm{H}$, Lindblom $\mathrm{U}$, Schmidt WC. Method for quantitative estimation of thermal thresholds in patients. J Neurol Neurosurg Psychiatry 1976;39:1071-1075.
33. Lefaucheur JP, Creange A. Neurophysiological testing correlates with clinical examination according to fibre type involvement and severity in sensory neuropathy. J Neurol Neurosurg Psychiatry. 2004;75:417-422.

34. Valls-Solé J, Schestatsky P, Veciana M. Exploraciones complementarias en el dolor neuropático. In: Serra J (Ed). Tratado de dolor neuropático. Madrid: Panamericana, 2006:221-231.

35. Schestatsky P, Gerchman F, Valls-Solé J Neurophysiological tools for small fiber assessment in patients with painful diabetic neuropathy. Pain Med 2009 [Epub ahead of print]

36. Sandrini G, Serrao M, Rossi P, Romaniello A, Cruccu G, Willer JC. The lower limb flexion reflex in humans. Prog Neurobiol 2005;77:353-395.

37. Dotson RM. Clinical neurophysiology laboratory tests to assess the nociceptive system in humans. J Clin Neurophysiol 1997;14:32-45.

38. Schestatsky P, Valls-Solé J, Costa J, León L, Veciana M, Chaves ML. Skin autonomic reactivity to thermoalgesic stimuli. Clin Auton Res 2007; 17:349-355.

39. Hansen HC, Treede RD, Lorenz J, Kunze K, Bromm B. Recovery from brainstem lesions involving the nociceptive pathways: comparison of clinical findings with laser-evoked potentials. J Clin Neurophysiol 1996;13:330-338.

40. Veciana M, Valls-Sole J, Schestatsky P, Montero J, Casado V. Abnormal sudomotor skin responses to temperature and pain stimuli in syringomyelia. J Neurol 2007;254:638-645.

41. Casey KL, Beydoun A, Boivie J, et al. Laser-evoked cerebral potentials and sensory function in patients with central pain. Pain 1996;64:485-491.

42. Garcia-Larrea L, Convers P, Magnin M, et al. Laser-evoked potential abnormalities in central pain patients: the influence of spontaneous and provoked pain. Brain 2002;125:2766-2781.

43. Chen AC, Niddam DM, Arendt-Nielsen L. Contact heat evoked potentials as a valid means to study nociceptive pathways in human subjects. Neurosci Lett 2001;316:79-82.

44. Schestatsky P, Lladó-Carbó E, Casanova-Molla J, Alvarez-Blanco S, Valls-Solé J. Small fibre function in patients with meralgia paresthetica. Pain 2008;139:342-348.

45. Peyron R, Laurent B, Garcia-Larrea L. Functional imaging of brain responses to pain. Areview and metaanalysis. Neurophysiol Clin 2000;30:263-288

46. McCarthy BG, Hsieh ST, Stocks A, et al. Cutaneous innervation in sensory neuropathies: evaluation by skin biopsy. Neurology 1995;45:1848-1855.

47. Holland NR, Stocks A, Hauer P, Cornblath DR, Griffin JW, McArthur JC. Intraepidermal nerve fiber density in patients with painful sensory neuropathy. Neurology 1997;48:708-711.

48. Atherton DD, Facer P, Roberts KM, Misra VP, Chizh BA, Bountra C. Use of the novel contact heat evoked potential stimulator (CHEPS) for the assessment of small fibre neuropathy: correlations with skin flare responses and intra-epidermal nerve fibre counts. BMC Neurol 2007;7:21.

49. Richeimer SH, Bajwa ZH, Kachramann SS, Ransil BJ, Warfield CA. Utilization patterns of tricyclic antidepressants in a multidisciplinary pain clinic: a survey. Clin J Pain 1997;13:324-329.

50. Finnerup NB, Johannesen IL, Sindrup SH, Bach FW, Jensen TS. Pain and dysaesthesia in patients with spinal cord injury: a postal survey. Spinal Cord 2001;39:256-262.

51. Beniczky S, Tajti J, Tímea Varga E, Vécsei L. Evidence-based pharmacological treatment of neuropathic pain syndromes. J Neural Transm 2005:112:735-749.

52. Meyerson BA. Neurosurgical approaches to pain treatment. Acta Anaesthesiol Scand 2001;45:1108-1113.

53. Cheing GL, Luk ML. Transcutaneous electrical nerve stimulation for neuropathic pain. J Hand Surg 2005;30:50-55.

54. Cruccu G, Aziz TZ, Garcia-Larrea L, et al. EFNS guidelines on neurostimulation therapy for neuropathic pain. Eur J Neurol 2007;14:952-970.

55. Pittler MH, Ernst E. Complementary therapies for neuropathic and neuralgic pain: systematic review. Clin J Pain 2008;24:731-733.

56. Lefaucheur JP, Drouot X, Ménard-Lefaucheur I, Keravel Y, Nguyen JP. Motor cortex rTMS restores defective intracortical inhibition in chronic neuropathic pain. Neurology 2006;67:1568-1574. 